\title{
Vinyl Polymerization. CCLVIII. Polymerization of Acrylonitrile Initiated by Tetramethyl- tetrazene and Dimethyl Maleate System
}

\author{
Kazuo Sugryama, Tadao Nakaya, and Minoru Imoto \\ Department of Applied Chemistry, Faculty of Engineering, Osaka City \\ University, Sugimoto-cho, Sumiyoshi-ku, Osaka, Japan.
}

(Received August 24, 1970)

\begin{abstract}
The polymerization of acrylonitrile (AN) initiated by the system of tetramethyltetrazene (TMT) and dimethyl maleate (DM) was carried out in dimethyl formamide. The polymerization proceeded through a radical mechanism. The initial rate of polymerization, $R_{p}$, was expressed by the following equation
\end{abstract}

$$
R_{p}=k[\mathrm{TMT}]^{0.57}[\mathrm{DM}]^{0.64}[\mathrm{AN}]^{2.00}
$$

A probable initiation mechanism was proposed according to the results of the kinetic studies and the data of NMR measurements of the TMT/DM system in the presence and absence of AN.

KEY WORDS Acrylonitrile/Tetramethyltetrazene / Dimethyl Maleate/

Radical Polymerization/Overall Kinetics/NMR/

In our earlier papers, ${ }^{1,2}$ it was shown that the tetramethyltetrazene (TMT) - acetic anhydride or the TMT-benzyl chloride system can initiate radical polymerizations of vinyl monomers. As an extension of these studies, we investigated the catalytic activities of four systems of TMT and diesters for the polymerization of acrylonitrile (AN) in dimethylformamide (DMF). The diesters employed were dimethyl maleate (DM), dimethyl fumarate, dimethyl phthalate, and dimethyl oxalate. The system of TMT and DM was found to be the most effective for the initiation of AN. It is interesting to note that the system of TMT and the corresponding trans isomer, dimethyl fumarate, had hardly any effect on the polymerization of AN. This paper is concerned with a kinetic study of the radical polymerization of $\mathrm{AN}$, in particular, with the TMT-DM system. A NMR study of the system in the presence and absence of AN was made.

\section{EXPERIMENTAL}

\section{Materials}

The dimethyl maleate, dimethyl fumarate, dimethyl phthalate, dimethyl oxalate, and 1,1- dimethylhydrazine were of commercial origin and purified by crystallization or distillation. TMT was prepared by the oxidation of 1,1-dimethylhydrazine with mercuric oxide, as described in earlier papers. ${ }^{1,2}$

Acrylonitrile (AN) and methyl methacrylate (MMA), styrene (St) and solvents employed were purified in the usual manner and redistilled under a stream of nitrogen before use.

\section{Polymerization Procedure}

The polymerization procedure was the same as those in the previous papers. ${ }^{1,2}$

\section{Characterization of the Polymer}

Chemical composition of the resulting polymer was determined from the results of its elemental analysis.

Weight-average mol wt of the polyacrylonitrile was calculated according to the following equation by Inagaki, et al. ${ }^{3}$

$$
\begin{array}{r}
{[\eta]=29.6 \times 10^{-5} M_{w}^{0.74}, \quad \mathrm{~d} l / g} \\
\left(\text { in DMF at } 30^{\circ} \mathrm{C}\right)
\end{array}
$$

\section{NMR Measurements}

NMR spectra were measured at $60 \mathrm{MHz}$, with a Hitachi-Perkin-Elmer R-20 spectrometer. 
Vinyl Polymerization. CCLVIII.

\section{RESULTS}

Polymerizations of Acrylonitrile Initiated by TMT and Various Diesters

Table I shows the results of the polymerizations of AN by TMT and various diesters. The diesters used were dimethyl maleate, dimethyl fumarate, dimethyl phthalate, and dimethyl oxalate.

Table I. Polymerizations of AN with some systems of $\mathrm{TMT}^{\mathrm{a}}$ and diesters in DMF at $70^{\circ} \mathrm{C}$ for $5 \mathrm{hr}^{\mathrm{b}}$

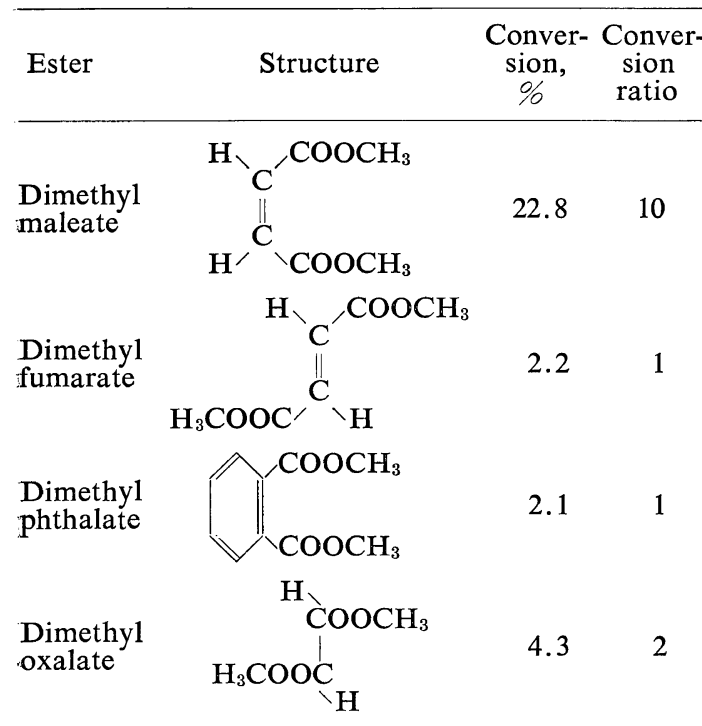

${ }^{a}$ In the polymerization of AN with TNT alone in DMF at $70^{\circ}$ for $5 \mathrm{hr}$, in which [TMT] was 2.1 $\times 10^{-2} \mathrm{~mol} / l$, the conversion was $0.35 \%$.

b $[\mathrm{TMT}]=[$ Diester $]=2.1 \times 10^{-2} \mathrm{~mol} / l$.

As can be seen from Table I, a TMT and DM system is the most effective of the four types of TMT-Diester systems. The resulting polymers were confirmed to be homopolymers of AN by elemental analyses and IR spectra.

Rate of Polymerization of AN with the TMTDM System

Homogeneous polymerization of AN was first carried out in DMF at $70^{\circ} \mathrm{C}$. The results are summarized in Table II. The data given in Table II are plotted in Figures 1 and 2.

The lines $\mathrm{A}$ and $\mathbf{B}$ show that the initial rate of polymerization is proportional to 0.57 power of [TMT] and to 0.64 power of [DM], respectively.
Table II. Reaction rate $\left(R_{p}\right)$ and weight-average degree of polymerization $\left(\boldsymbol{P}_{w}\right)$ of the polymer resulting from the polymerization of $\mathrm{AN}$ in DMF at $70^{\circ} \mathrm{C}$ with the TMT/DM system

\begin{tabular}{ccccr}
\hline $\begin{array}{c}\text { [AN], } \\
\mathrm{mol} / l\end{array}$ & $\begin{array}{c}{[\mathrm{TMT}]} \\
\times 10^{2}, \\
\mathrm{~mol} / l\end{array}$ & $\begin{array}{c}{[\mathrm{DM}]} \\
\times 10^{2}, \\
\mathrm{~mol} / l\end{array}$ & $\begin{array}{c}\boldsymbol{R}_{p} \times 10^{5}, \\
\mathrm{~mol} / \mathrm{lsec}\end{array}$ & $\boldsymbol{P}_{w}$ \\
\hline 4.56 & 0.53 & 2.10 & 0.50 & 1620 \\
4.56 & 1.05 & 2.10 & 1.80 & 1510 \\
4.56 & 4.20 & 2.10 & 2.93 & 1120 \\
4.56 & 8.40 & 2.10 & 3.00 & 980 \\
4.56 & 2.10 & 0.53 & 1.04 & 2320 \\
4.56 & 2.10 & 1.05 & 1.64 & 1920 \\
4.56 & 2.10 & 2.10 & 2.02 & 1280 \\
4.56 & 2.10 & 4.20 & 1.93 & 1220 \\
4.56 & 2.10 & 8.40 & 1.64 & 850 \\
1.52 & 2.10 & 2.10 & 0.46 & - \\
2.28 & 2.10 & 2.10 & 0.98 & - \\
3.04 & 2.10 & 2.10 & 1.43 & - \\
3.80 & 2.10 & 2.10 & 2.25 & - \\
\hline
\end{tabular}

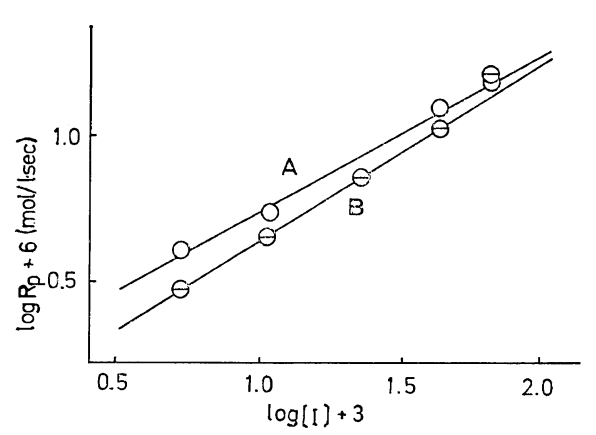

Figure 1. Rate of polymerization $\left(R_{p}\right) \quad v s$. concentration of the initiator system in the polymerization of AN with the TMT-DM system (I) in DMF at $70^{\circ} \mathrm{C}:$ line $\mathrm{A},[\mathrm{AN}]=4.56 \mathrm{~mol} / l,[\mathrm{DM}]$ $=2.1 \times 10^{-3} \mathrm{~mol} / l,[\mathrm{I}]=[\mathrm{TMT}]$ was varied; line $\mathrm{B}$, $[\mathrm{AN}]=4.56 \mathrm{~mol} / l, \quad[\mathrm{TMT}]=2.1 \times 10^{-3} \mathrm{~mol} / l, \quad[\mathrm{I}]=$ [DM] was varied.

It appears from Figure 2 that the initial rate of polymerization is proportional to 2.00 power of [AN]. Thus, the following rate equation is obtained.

$$
R_{p}=k[\mathrm{TMT}]^{0.57}[\mathrm{DM}]^{0.64}[\mathrm{AN}]^{2.00}
$$

\section{Estimation of Overall Activation Energy}

The homogeneous polymerization of AN initiated by the TMT-DM system was carried out in DMF, changing the temperature in the range 


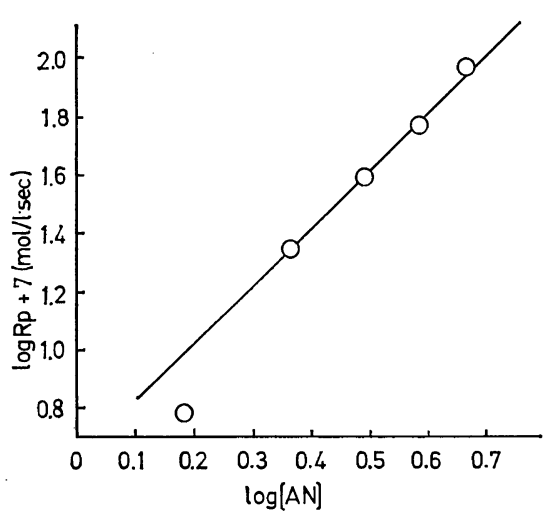

Figure 2. Rate of polymerization $\left(R_{p}\right)$ vs. ANconcentration ; $[\mathrm{TMT}]=[\mathrm{DM}]=2.1 \times 10^{-3} \mathrm{~mol} / l$ in the polymerization of AN with TMT-DM system in DMF at $70^{\circ} \mathrm{C}$.

60 to $80^{\circ} \mathrm{C}$, where both [TMT] and [DM] were kept constant at $2.10 \times 10^{-3} \mathrm{~mol} / l$. By an Arrhenius plot of $R_{p}$ vs. $1 / T$ (Figure 3 ), the overall activation energy was estimated as $11.9 \mathrm{kcal} / \mathrm{mol}$. This value is lower than that obtained by using the TMT alone, and is near the value obtained by using the TMT-benzyl chloride system, as compared in Table III.

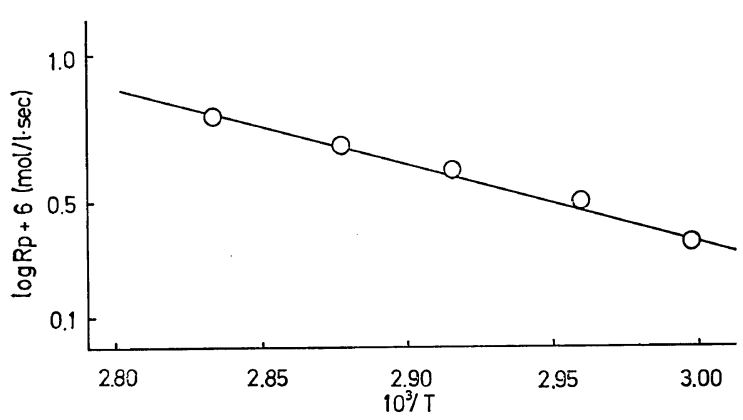

Figure 3. Arrhenius plot of $\log R_{p}$ vs. $1 / T$.

Table III. The overall activation energies of the polymerization of AN with TMT alone TMT $-\mathrm{AA}$, and TMT-DM systems ${ }^{\mathrm{a}}$

\begin{tabular}{lcccc}
\hline Initiator & TMT $^{1}$ & $\begin{array}{c}\text { TMT } \\
- \text { AA }^{1}\end{array}$ & $\begin{array}{l}\text { TMT } \\
- \text { BC }^{2}\end{array}$ & $\begin{array}{c}\text { TMT } \\
-\mathrm{DM}\end{array}$ \\
\hline $\begin{array}{c}\text { Activation } \\
\text { energy } \\
\text { kcal/mol }\end{array}$ & $25-4$ & 12.6 & 11.4 & 11.9 \\
\hline
\end{tabular}

a AA and BC represent acetic anhydride and benzyl chloride, respectively.
Confirmation of Radical Mechanism of Polymerization with the TMT-DM System

Hydroquinone inhibited the polymerization of AN initiated by the TMT-DM system. Furthermore, the copolymerization of MMA with styrene ( $\mathrm{St}$ ) was carried out in bulk at $40^{\circ} \mathrm{C}$. Figure 4 shows the composition curve of the copolymers obtained, which is characteristic of a radical copolymerization.

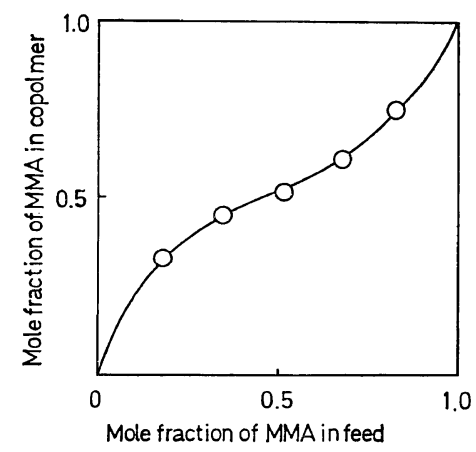

Figure 4. Composition curve for the bulk copolymerization of MMA with styrene at $40^{\circ} \mathrm{C}$; [TMT] $=[\mathrm{DM}]=2.1 \times 10^{-2} \mathrm{~mol} / l$.

It may therefore be concluded that polymerization with the initiating system of TMT and DM proceeds by a radical mechanism.

\section{Solvent Effect}

The polymerization of MMA was carried out in various solvents, since the use of $\mathrm{AN}$ is unsuitable for the effect of solvents on the rate of polymerization to be observed. Figure 5 shows

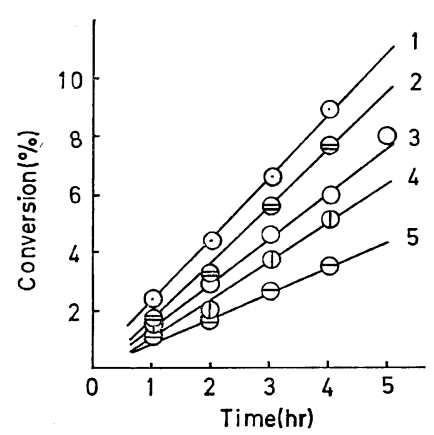

Figure 5. Solvent effect on the rate of polymerization of MMA with the TMT-DM system at $50^{\circ} \mathrm{C} ;[\mathrm{MMA}]=2.81 \mathrm{~mol} / l,[\mathrm{TMT}]=[\mathrm{DM}]=2.1 \times$ $10^{-2} \mathrm{~mol} / l ; 1$, benzonitrile; 2 , DMF 3 , cyclohexanone; 4 , anisole; 5 , benzene. 
the effect of the solvent on the rate of polymerization, which decreases with the following order of solvents

(1) benzonitrile $>$ (2) DMF $>$ (3) cyclohexanone $>$

(4) anisole $>$ (5) benzene

The order is the same in the polymerization of MMA with the TMT-benzyl chloride system, ${ }^{2}$ the rate of polymerization being greater in a polar solvent.

Attempted Detection of ESR Signal in the TMT$D M$ and TMT-Benzyl Bromide Systems

No ESR signal was obtained in the reaction between TMT and DM in DMF or benzene at 25 or $50^{\circ} \mathrm{C}$. An attempt to detect the ESR signal in the reaction between TMT and DM in the presence of $\mathrm{AN}$ in $\mathrm{DMF}$ at $50^{\circ} \mathrm{C}$ was also unsuccessful.

On the other hand, as seen in Figure 6, the treatment of TMT with benzyl bromide in benzene at $25^{\circ} \mathrm{C}$ immediately yielded a highly resolved ESR spectrum characteristic of the tetramethylhydrazine radical cation $\left(\mathrm{TMH}^{+} \cdot\right){ }^{4-6}$

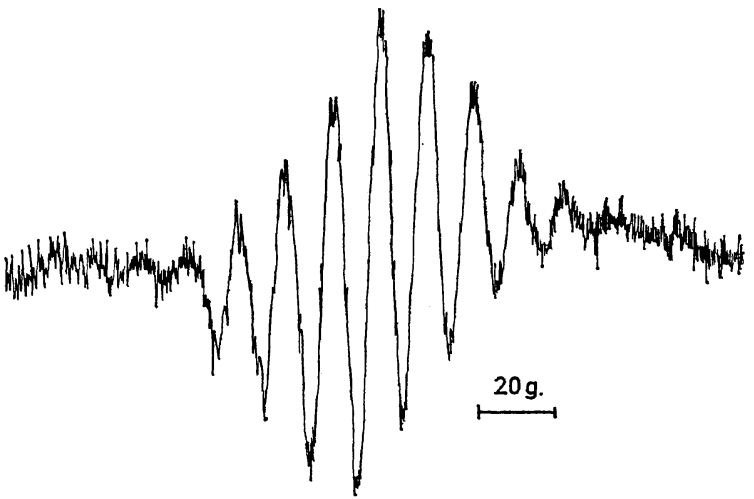

Figure 6. FSR spectrum of tetramethyl hydrazine radical cation derived from TMT and benzyl bromide.

According to Romans, et al., who had studied the reaction of TMT with phthalic anhydride, ${ }^{5}$ the radical cation may be formed from the following scheme

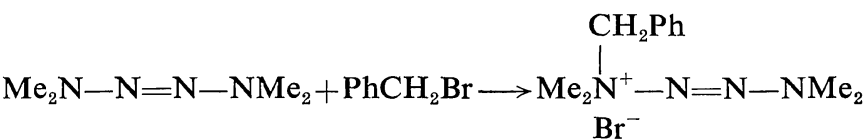

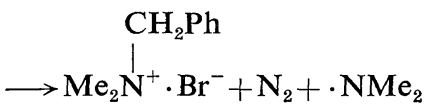

$$
\begin{aligned}
& 2 \cdot \mathrm{NMe}_{2} \longrightarrow \mathrm{Me}_{2} \mathrm{~N}-\mathrm{NMe}_{2} \\
& \mathrm{Me}_{2} \mathrm{~N}-\mathrm{NMe}_{2}+\mathrm{Me}_{2} \stackrel{\mathrm{N}^{+}}{\mathrm{CH}_{2} \mathrm{Ph}} \longrightarrow \mathrm{Me}_{2} \stackrel{+}{\mathrm{N}}-\mathrm{NMe}_{2}+\mathrm{PhCH}_{2} \mathrm{NMe}_{2} \\
& \left(\mathrm{TMH}^{+}\right. \text {.) }
\end{aligned}
$$

NMR Measurements of the TMT-DM System

In order to obtain information on the radical species in the polymerization initiated with the TMT-DM system, NMR spectra of the nearly equimolar reaction mixture of TMT and DM in the presence and absence of AN were taken in deuterochloroform at room temperature. For comparison, the NMR data of TMT, DM, dimethyl fumarate, and AN are tabulated in Table IV.

Figure 7 shows the NMR spectral changes in the reaction between TMT and DM.

The NMR spectrum of the initial reaction mixture of TMT and DM is shown in Figure 7 IIa. The methyl peak of TMT shifted considerably upfied by $2.85 \mathrm{ppm}$. In explanation of
Table IV. NMR data of TMT, DM, dimethyl fumarate, and $\mathrm{AN}$ (in $\mathrm{CDCl}_{3}$ )

\begin{tabular}{lcc}
\hline Compound & $\begin{array}{c}\text { Peak range } \\
\delta, \mathrm{ppm}\end{array}$ & Assignment \\
\hline TMT & $5.60-5.70$ & Methyl protons \\
DM & $3.80-3.90$ & Carbomethoxy protons \\
& $6.35-6.45$ & Olefinic protons \\
Dimethyl & $3.75-3.85$ & Carbomethoxy protons \\
fumarate & $6.85-6.95$ & Olefinic protons \\
H(1) H(2) & $6.05-6.15$ & H(1) \\
C $=C^{\prime}$ & $5.40-5.80$ & H(2) \\
H(3) Cे & $5.80-6.00$ & $\mathrm{H}(3)$ \\
\multicolumn{1}{c}{ (AN) } & & \\
\hline
\end{tabular}

this shift, it is possible that tetramethylhydrazine $^{7,8}$ may have been formed by the decomposi- 


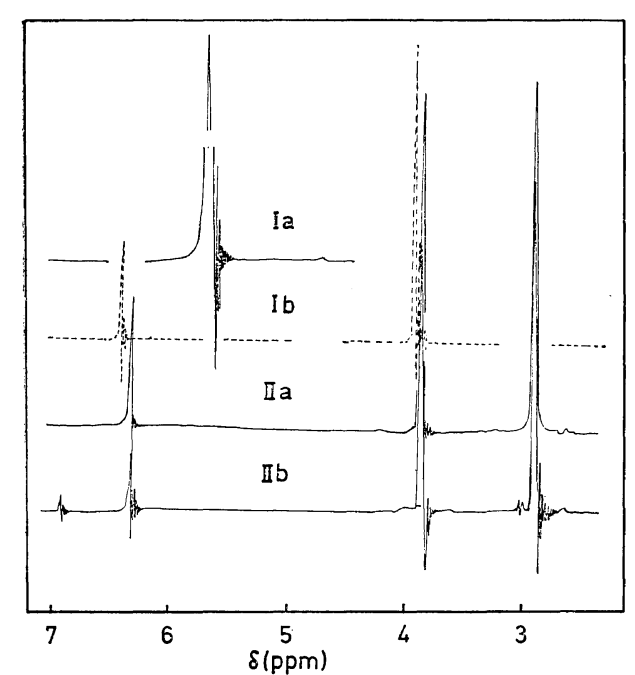

Figure 7. NMR spectral changes in the course of the reaction between TMT and DM; TMT, 1.25 $\mathrm{m} \mathrm{mol} ; \mathrm{DM}, 1.19 \mathrm{~m} \mathrm{~mol} ; \mathrm{CDCl}_{3}, 4 \mathrm{ml}$; spectra of TMT (Ia) and -----, DM (Ib).

Spectrum (IIa) was taken one min after mixing TMT and DM.

Spectrum (IIb) was taken $40 \mathrm{hr}$ after mixing TMT and DM.

tion of TMT by DM. This point is now under investigation. The peaks due to olefinic protons and methoxycarbonyl protons of DM shifted upfield by $0.07 \mathrm{ppm}$ and $0.08 \mathrm{ppm}$, respectively. On standing for $40 \mathrm{hr}$, a new small peak appeared at $6.9 \mathrm{ppm}$, as shown in Figure $7 \mathrm{IIb}$. This was due to a small amount of dimethyl fumarate formed by the reaction of TMT with DM. The presence of dimethyl fumarate was confirmed by the isolation of dimethyl fumarate from the reaction of TMT and DM for one week in high yields.

Addition of AN to the TMT-DM system did not essentially cause the spectral change of the peaks at $2.8 \mathrm{ppm}$ and $3.8 \mathrm{ppm}$, though the spectral change of the peak at $6.25 \mathrm{ppm}$ was not clear because of the overlapping with olefinic peaks of AN.

\section{DISCUSSION}

From the results given above, it was concluded that the polymerization of AN initiated by the TMT-DM system proceeded through a free radical mechanism. The rate of the polymerization was proportional to 0.57 power of [TMT], 0.64 power of $[\mathrm{DM}]$, and 2.00 power of [AN].

Considering the rate equation resulting, the following elementary reactions may be written, according to Thomas, et al..$^{9,10}$

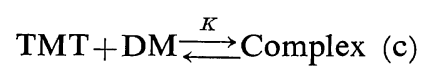

Initiation

$$
\mathrm{C}+\mathrm{M} \stackrel{k_{1}}{\longrightarrow} 2 \mathrm{R} \text {. }
$$

Propagation $\quad \mathbf{R} \cdot+\mathbf{M} \stackrel{k_{2}}{\longrightarrow} \mathbf{R}$.

Transfer to solvent

$$
\mathrm{R} \cdot+\mathrm{S} \stackrel{k_{3}}{\longrightarrow} \mathrm{RH}+\mathrm{S} \cdot
$$

Addition to solvent radical

$$
\mathrm{S} \cdot+\mathrm{M} \stackrel{k_{4}}{\longrightarrow} \mathrm{R} \cdot
$$$$
\text { Termination }\left\{\begin{array}{l}
\mathrm{S} \cdot+\mathrm{R} \cdot \stackrel{{ }_{5}}{\longrightarrow} \mathrm{SR} \\
\mathrm{S} \cdot+\mathrm{S} \cdot \stackrel{k_{6}}{\longrightarrow} \mathrm{SS} \\
\mathbf{R} \cdot+\mathrm{R} \cdot \stackrel{k_{7}}{\longrightarrow} \mathrm{RR}
\end{array}\right.
$$

where $\mathrm{M}, \mathrm{R} \cdot$, and $\mathrm{S}$ represent monomer, radical, and solvent, respectively. In eq 4 , we considered that the radical formation is performed by the reaction of an AN monomer with a complex formed from TMT and DM. When a steady state is reached, $\mathrm{dR} \cdot / \mathrm{d} t=0$ and $\mathrm{dS} \cdot / \mathrm{d} t=0$.

$$
\begin{aligned}
& k_{1}(\mathrm{C})(\mathrm{M})+k_{4}(\mathrm{~S} \cdot)(\mathrm{M}) \\
& \quad=k_{3}(\mathrm{R} \cdot)(\mathrm{S})+k_{5}(\mathrm{~S} \cdot)(\mathrm{R} \cdot)+k_{7}(\mathrm{R} \cdot)^{2} \\
& k_{3}(\mathrm{R} \cdot)(\mathrm{S})=k_{4}(\mathrm{~S} \cdot)(\mathrm{M})+k_{5}(\mathrm{~S} \cdot)(\mathrm{R} \cdot)+k_{6}(\mathrm{~S} \cdot)^{2}
\end{aligned}
$$

In order to obtain a useful solution for $\mathbf{R}$., according to Thomas, et al. ${ }^{9} k_{5}(\mathrm{~S} \cdot)(\mathrm{R} \cdot)$ and $k_{6}(\mathrm{~S} \cdot)^{2}$ in eq 12 were ignored, because $(\mathrm{M})$ is very much larger than $(\mathbf{S} \cdot)$ and $(\mathbf{R} \cdot)$. Thus the following equation is obtained

$$
\begin{aligned}
R_{p}=( & \left.k_{1} K\right)^{0.5} k_{2}[\mathrm{TMT}]^{0.5}[\mathrm{DM}]^{0.5}[\mathrm{M}]^{1.5} \\
& \times\left[k_{7}+\frac{k_{3} k_{5}[\mathrm{~S}]}{k_{4}[\mathrm{M}]}\right]^{-0.5}
\end{aligned}
$$

Eq 13 predicts the square root dependence on the initiator and a monomer exponent between 1.5 and 2.0, depending on the solvent concentration and the values of the rate constants. Eq 13 closely agrees with the experimental rate equation.

The rate of polymerization was proportional 
to the same order of [TMT] and [DM]. The rate of polymerization of MMA initiated by the TMT-DM system increased with the polarity of the solvent, though, in the case of AN, the effect of the polarity of the solvent is obscure. Furthermore, from NMR measurements, the methyl peak of TMT shifted considerably upfield with the addition of DM to TMT. On the other hand, the olefinic protons of DM also shifted upfield by addition of TMT to DM. This suggests, initially, the nucleophlic attack of the neutral dimethylamino nitrogen of TMT upon the ester carbonyl carbon, ${ }^{11,12}$ as shown below. As a consequence of the partial bond formation between the dimethylamino nitrogen of TMT and the carbonyl carbon of DM, it may be considered that the partial positive charge on the carbonyl carbon develops and the electron on the double bond of DM moves to the carbonyl carbon. In this situation, we expect that there will not be much of a double bond character between the ethylenic carbons in DM. Therefore, rotation about the bond axis occurs easily under these circumstances so that DM should be interconverted into the corresponding trans isomer, dimethyl fumarate.

Thus the initiation mechanism in which the AN monomer is involved may be considered to be as follows ${ }^{13,14}$

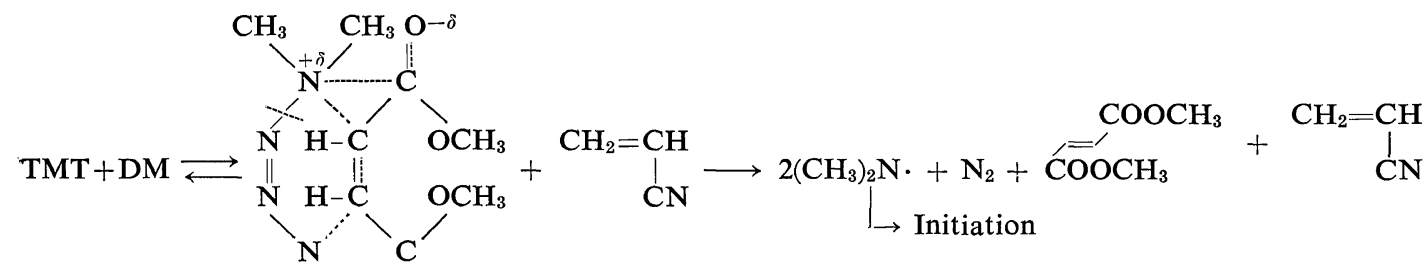

As shown in the above scheme, when both TMT and DM molecules are in the form of cistype $\mathrm{e}^{15,16}$ the reaction proceeds. The interaction of the nitrogen atoms of dimethylamino groups in TMT and the ethylenic carbon atoms of DM may form a six-membered ring and enhance to make a molecular complex. Such an interaction would be little expected to occur in combinations of TMT with the other diesters. The initiating species of the polymerization may be the dimethylamino radical derived from homolytic scission of the weakest $>\stackrel{+\delta}{\mathrm{N}}-\mathrm{N}=$ bond.

\section{REFERENCES}

1. T. Nakaya, Y. Maki, and M. Imoto, Makromol. Chem., 113, 131 (1968).

2. T. Nakaya, Y. Maki, and M. Imoto, Makromol. Chem., 125, 161 (1969).

3. N. Inagaki, K. Hayashi, and T. Matsuo, Makromol. Chem., 84, 80 (1965).

4. S. F. Nelsen, J. Amer. Chem. Soc., 88, 5666
(1966).

5. C. J. Michejda and D. Romans, Tetrahedron Letters, 4213 (1969).

6. D. Romans, W. H. Bruning, and C. J. Michejda, J. Amer. Chem. Soc., 91, 3859 (1969).

7. S. F. Nelsen, R. B. Metzler, and M. Iwamura, J. Amer. Chem. Soc., 91, 5103 (1969).

8. R. T. Beltrami and E. R. Bissell, J. Amer. Chem. Soc., 78, 2468 (1956).

9. W. M. Thomas, E. H. Gleason, and J. J. Pellon, J. Polym. Sci., 17, 275 (1955).

10. P. F. Onyon, Trans. Faraday Soc., 52, 80 (1956).

11. W. P. Jencks and M. Gilchrist, J. Amer. Chem. Soc., 90, 2622 (1968).

12. B. Holmquist and T. C. Bruice, J. Amer. Chem. Soc. 91, 2985 (1969).

13. W. M. Tolles, D. M. Moose, and W. E. Thun, J. Amer. Chem. Soc., 88, 3476 (1966).

14. B. G. Gowenlock, P. P. Jones, and D. R. Snelling, Can. J. Chem., 41, 1911 (1963).

15. W. E. Bull, J. A. Seaton, and L. F. Audrieth, J. Amer. Chem. Soc., 80, 2516 (1958).

16. N. R. Fetter, F. E. Brinckman, Jr., and D. W. Moore, Can. J. Chem., 40, 2184 (1962). 